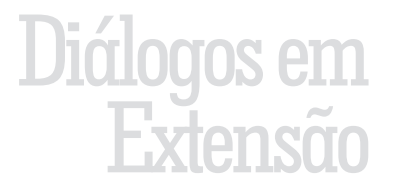

\title{
A preservação e divulgação do patrimônio histórico da RPPN - Santuário do Caraça
}

Flávio Augusto de Freitas Teixeira ${ }^{1}$, Karla Denise Martins ${ }^{2}$

RESUMO: Este relato de experiência é resultado das atividades desenvolvidas pelo "Projeto Dom Viçoso no Santuário do Caraça: um percurso sobre a vida do prelado de Mariana". O projeto visa identificar e iniciar o processo de preservação do acervo documental Caracense, bem como, a partir daí, criar um Museu Litúrgico, visando à divulgação desses materiais aos visitantes do Santuário, cujo número é de aproximadamente setenta mil anualmente.

Palavras-chave: Dom Viçoso, lazaristas, patrimônio histórico, Santuário do Caraça.

Áreas temáticas: Cultura e educação.

\footnotetext{
Graduando do Curso de História da Universidade Federal de Viçosa. Bolsista do Programa Institucional de Bolsas de Extensão (PIBEX-UFV) em 2011. E-mail: flavio.teixeira@ufv.br

2 Doutora em História Cultural pela Unicamp. Professora do Departamento de História da Universidade Federal de Viçosa. Coordenou o Projeto Dom Viçoso no Santuário do Caraça: um percurso sobre a vida do prelado de Mariana. E-mail: karlamartins@ufv.br
} 


\section{Preservation and disclosure of historical patrimony RPPN - Santuário do Caraça}

ABSTRACT: This experience report results from activities developed by the Project Dom Viçoso in the Sanctuary of Caraça: a course on the living of Mariana's bishop. The project aims to identify and begin the preservation process of the Caracense documentary for creating a Liturgical Museum, aiming to disclosure those materials to visitors, whose number is approximately seventy thousand annually.

Keywords: Dom Viçoso, historical patrimony, Sanctuary Caraça, Vicentians.

Thematic areas: Culture and education.

\section{La preservación y revelación del patrimonio histórico de RPPN - Santuário do Caraça}

RESUMEN: Este relato de experiencia es el resultado de las actividades desarrolladas por el Proyecto Dom Viçoso en el Santuario de Caraça: un curso de la vida del bispo de Mariana. El proyecto tiene el objetivo de identificar y comenzar el proceso de preservación documental colección Caracense, y crear un Museo Litúrgico con el objetivo de revelación esos materiales a los visitantes del santuario, cuyo número es aproximadamente setenta mil anuales.

Palabras clave: Dom Viçoso, herencia, Santuário do Caraça, Vicentians.

Áreas temáticas: Cultura y educación. 


\section{OS PRIMÓRDIOS DO CARAÇA PORTUGUÊS}

Fundado no final do século XVIII pelo português conhecido por Irmão Lourenço de Nossa Senhora ${ }^{1}$, o Santuário do Caraça foi em seus primeiros anos um eremitério e centro de peregrinação. No vale da Serra do Espinhaço, região de Catas Altas, Irmão Lourenço erigiu uma capela em estilo barroco e dois prédios que a ladeavam, onde se hospedavam os peregrinos e seus irmãos de hábito da Ordem de São Francisco de Assis. Após a morte do cenobita, já em 1820, o Santuário passou a pertencer à Congregação da Missão de São Vicente de Paulo², graças à doação da sesmaria por D. João VI aos lazaristas recém-chegados de Portugal para a realização de missões no Brasil. Eram eles os missionários Pe. Leandro Rebello Peixoto e Castro e Pe. Antônio Ferreira Viçoso, que em 1820, iniciaram as atividades de ensino com a criação de um Colégio nas depen-

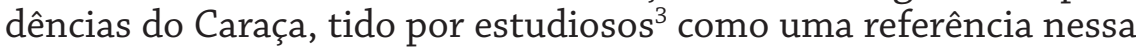
área durante todo o Segundo Império Brasileiro, até 1968, quando um incêndio interrompeu os seus serviços de ensino e formação sacerdotal.

Em 1955, por seu valor histórico, arquitetônico e paisagístico, o Caraça foi tombado pelo antigo SPHAN - Serviço do Patrimônio Histórico e Artístico Nacional, hoje IPHAN - Instituto do Patrimônio Histórico e Artístico Nacional. Em 1970, foram iniciadas as reformas dos prédios afetados pelo incêndio, bem como a construção de instalações voltadas ao turismo e recepção de visitantes de toda a ordem (alunos, professores, pesquisadores, curiosos etc.), assim como é de praxe em muitos antigos mosteiros e igrejas na Europa. Já em 1974, o Conselho Nacional de Serviço Social (CNSS) reconheceu o Santuário como Entidade de Fins Filantrópicos. Com a Constituição Mineira de 1989, um novo aparato jurídico foi acionado na defesa do Santuário do Caraça, agora no sentido da preservação do seu acervo natural. Desta forma, a Serra do Caraça foi tombada e declarada Monumento Natural do Estado de Minas Gerais. Recentemente, em janeiro de 2012, o Caraça foi eleito, por consulta popular, uma das sete Maravilhas da Estrada Real. Apesar do reconhecimento dessas instituições sobre a importância cultural do Santuário com todo o seu complexo estrutural, ainda há muito para fazer, especialmente no que se refere à preservação e tombamento.

Muitos pesquisadores desenvolvem projetos que tratam da fauna e flora caracense, havendo também, em menor escala, aqueles ligados à história do Colégio e das missões lazaristas. Com essas investigações, o Santuário tem recebido analistas do mundo todo. Alguns artigos estão disponíveis para pesquisa na Biblioteca do San- 
tuário e outros podem ser encontrados na internet. No entanto, há um acervo cultural e histórico que precisa ser explorado pelos mais diversos estudos. Pode-se tomar como exemplo o acervo da biblioteca. Desde o século XIX, graças aos esforços dos padres lazaristas, como os franceses Júlio Clavelin e Miguel Maria Sípolis, o acervo bibliográfico chegou a contar com nada menos de 50.000 volumes, destacando-se entre eles livros raros de traduções em latim e grego dos clássicos da literatura grega e romana, além de exemplares de grandes teólogos como Santo Agostinho. Nesses livros, é possível encontrar anotações, rabiscos, grifos e até intervenções que ajudam a pensar nas escolhas daqueles leitores do Colégio e Seminário. Tais escritos também informam convicções, silenciosas à primeira vista, e nos levam ao estudo de comportamentos dos personagens em textos oficiais.

Além da Biblioteca, há também o Arquivo, que conta com documentos em suporte de papel, como cartas, bilhetes, manuais de catecismo, diários de classe, livros caixa etc., e o arquivo fotográfico, contando com cerca de 4.500 unidades que, em sua maioria, necessitam ser identificadas e catalogadas. Também localizado no prédio do antigo Colégio, há o Museu que expõe objetos do cotidiano escolar de alunos e padres do Caraça, como máquinas de costura, objetos de cama, mesa e banho, e claro, aqueles ligados à vida religiosa, como batinas e imagens de santos. No entanto, esse Museu expõe as peças sem um roteiro ou temática específica. A disposição dos objetos não possui uma discussão adjacente que a justifique, portanto, é ainda um grupo de peças expostas e não um museu no sentido moderno. Atualmente a concepção de museu transcende a ideia de "ajuntamento de peças", propõe um tema, uma discussão conceitual e a constante interação com o tempo corrente. A partir da década de 1960, André Malraux, escritor em assuntos culturais e políticos na França, propôs o "Museu integral", ou seja, a interação entre a "realidade material e virtual". Essa concepção foi ampliada posteriormente dando lugar à mudança da ideia de museu e nos coloca a questão da interatividade e a pergunta: o museu é para os que morreram ou para os que vivem? Bem, embora seja importante a memória passada como elemento a ser preservado, os sujeitos responsáveis por pensar a memória não são os mortos, mas aqueles que a retiram dos túmulos e a faz presente.

Há um espaço no Caraça que erroneamente é chamado de Pinacoteca, onde é possível encontrar, além de outros objetos espalhados, vários quadros sem tratamento e devido cuidado. Em situação igual estão objetos, tais como: rosários, castiçais, pequenos livros, 
crucifixos, armários antigos e outros materiais utilizados pelos sacerdotes, incluindo relíquias de valor apenas religioso e histórico. Tais objetos que ali estão necessitam de ações urgentes para organização, higienização, restauração e acondicionamento.

Os objetos que perfazem o patrimônio no Santuário do Caraça permitem, por exemplo, o conhecimento do cotidiano tanto nas atividades de ensino quanto nas ordinárias. Os diários de estudantes figuram entre os relatos mais importantes, uma vez que traduzem a perspectiva dos internos, seus medos, suas relações, sendo possível pelo desligamento dos cargos e grilhões próprios dos que administravam a instituição. Um exemplo disso é possível encontrar no livro de Augusto Costa Leite e Milton Junqueira Leite, "Saudades e Lembranças", publicado em 1946, no qual os autores expõem impressões inéditas do cotidiano de um aluno daquele recinto, como notado no fragmento:

Os padres tinham mesa à parte e servente especial, razão pela qual as iguarias que saboreavam ficavam à sua inteira disposição. O mesmo, entretanto, não acontecia com os colegiais, distribuídos em mesas compridas e obrigados, para se servirem, a ficar à espera uns dos outros (Leite, 1946 apud ANDRADE, 2000, p.140).

Outro livro destacado é o de Luis Felipe Vieira Souto, "Dispersos: vida e obra de um escritor esquecido", de 1936. No livro de Souto (1936, apud ANDRADE, 2000, p.140) há 23 cartas para os familiares, nas quais ressalta as suas impressões sobre os internos e suas relações naquele Colégio e Seminário entre 1868 e 1869. Ao entrarmos em contato com esse livro, entendemos a importância de uma intervenção na busca da história cotidiana do Caraça e, às vezes, uma memória que pode nos ajudar a entender relações e tensões naquele ambiente de reclusão e ensino.

Foi desta forma, a partir de uma constatação das necessidades que se fazem para as melhorias da preservação e divulgação deste patrimônio, que pensamos esse projeto para uma intervenção mais efetiva na recuperação e organização das fontes que lá se encontram. Este conhecimento servirá não só ao Caraça, como também a toda sociedade. Pretendemos ainda escrever sobre a História da Igreja de Minas Gerais e dar a conhecer uma face de uma sociedade mineira pós-"decadência" aurífera, tão esquecida nos livros didáticos e, muitas vezes, negligenciada pela historiografia. Grande parte da população desconhece que um dos motivos da ausência de ordens religiosas na região em Minas parece ter findado com a decadência de exploração do ouro, mas havia povoados para serem conhecidos 
e evangelizados. Com a chegada da família real, em 1808, D. João VI percebeu essa necessidade e trouxe para a província mineira a Congregação da Missão de São Vicente de Paulo, que já conhecia bem em Portugal, instalada naquele país desde 1716 pelo missionário Pe. Gomes da Costa.

Um dos mais importantes lazaristas nas Minas Gerais foi D. Antônio Ferreira Viçoso, fundador do Colégio do Caraça e Superior da casa. Exerceu papel fundamental para o processo de projeção da excelência do ensino caracense, especialmente com o estudo dos autores greco-romanos e o incentivo ao conhecimento de filosofia laica e canônica. Os professores do Caraça priorizavam as matérias de humanidades e sua estrutura pedagógica assemelhava-se aos principais institutos religiosos franceses, como Bourges e Saint Sulpice ${ }^{4}$. Em 1833, Pe. Viçoso foi eleito, por seus co-irmãos, Superior Geral da Congregação da Missão no Brasil. E em 1844, tornou-se Bispo de Mariana por nomeação de D. Pedro II. Faleceu em Mariana, sede do Bispado, em 1875, com a idade de 88 anos. Por meio do estudo da trajetória de D. Viçoso, é possível entender uma face importante da ação clerical em Minas Gerais e no Brasil de modo geral, além de compreender a reestruturação das Paróquias a partir das experiências pastorais do Bispo, cuja ação missionária se estendeu por mais de 140 paróquias e vilas. As visitas pastorais e a ação dos missionários da Congregação da Missão fizeram renascer a Igreja institucional nessas terras.

Apesar disto, por uma soma de motivos, a intervenção para preservar o patrimônio caracense não foi suficiente e os objetos vêm sofrendo sérios danos. Sabendo disto, decidimos, junto à Direção do Santuário, dar início a uma série de atividades de parcerias entre um grupo de pesquisadores e os trabalhadores do Santuário para a organização e divulgação do acervo referente à D. Viçoso, com vistas à ampliação aos demais objetos dos padres Lazaristas. Estas ações de resgate e divulgação foram os primeiros passos para o necessário processo de preservação e acesso daquele singular acervo. Além da preocupação em organizar e divulgar a memória dos padres e dos alunos do Colégio, nosso intuito é que posteriormente possamos também entender a questão dos escravos e a presença das mulheres (conhecidas como Sampáias) no Santuário.

\section{DISCUSSÃO METODOLÓGICA}

De acordo com o cronograma de atividades formulado para o Projeto em questão, as primeiras atividades realizadas foram reuniões com a equipe envolvida ${ }^{5}$ para pensar ações e metas de execução. 
Seguindo ainda as necessidades da execução, realizamos a pesquisa bibliográfica para a confecção de textos explicativos on-line, artigos, banners, folders, palestras e exposição temática proposta em um evento que abordaremos a seguir. Muitos professores e alunos da região não conhecem a história desse patrimônio e mal sabem a importância de sua existência na história local. Isso porque, nos materiais didáticos, a História das Minas encerra-se com dois fatos em particular: história da exploração aurífera e Inconfidência Mineira. O desenvolvimento de várias cidades, ao longo do século XIX, raramente é evidenciado nas escolas de Minas Gerais.

Os textos foram previamente selecionados, podendo ser divididos em duas categorias: os que tratavam de assuntos relacionados à História da Igreja Católica no Brasil e História da Educação, e a outra categoria referente ao estudo do patrimônio, do resgate e difusão de acervos documentais, bem como análise das leis de preservação histórica. Desta forma, compreendemos que a prática de pesquisa também é imprescindível para a execução de trabalhos de cunho extensionista, já que foi necessária a produção de conhecimento sobre fatos e situações talvez desconhecidas na maior parte dos estudos sobre o Bispo, sem perder de vista a divulgação e a troca de conhecimento para a comunidade de Catas Altas e região.

Parte do acervo referente ao Bispo está localizada na antiga Pinacoteca, no armário ao qual atribuímos o nome de "Armário D. Viçoso". O conjunto de documentos depositados neste local é formado, em sua maioria, por objetos de uso litúrgico e pessoal, manuscritos como correspondências, anotações, Livros de Sermões e também algumas relíquias de D. Viçoso (Solidéu, Cruz Missionária, Pedaços de roupa, fragmentos de ossos etc.). Estes documentos precisavam de uma prévia intervenção como higienização, catalogação e restauração para o correto arquivamento e/ ou exposição. Para tanto, a equipe, após ter buscado informações com especialistas na área, conseguiu uma parcial intervenção nas ações acima descritas.

Como na Pinacoteca, há no Museu do Caraça quadros e relíquias de toda a ordem, cuja posse pode ter sido de D. Viçoso. Dissemos pode ter pertencido, pois estamos em fase de identificação com a ajuda das biografias escritas sobre o Bispo e seu inventário/testamento. Já no Arquivo encontravam-se algumas fotografias e documentos higienizados, catalogados, arquivados em condições adequadas.

$\mathrm{O}$ acesso a estas fontes de posse restrita é difícil, dadas as condições de pesquisa e o envolvimento emocional daqueles que preservam tal memória, o que é perfeitamente compreensível ${ }^{6}$. No entan- 
to, embora as dissertações e as teses tenham ampliado a imagem de muitos homens e mulheres da Igreja, há ainda um anseio por uma recordação da História Religiosa quanto às ações de dirigentes e figuras emblemáticas. A história da Congregação da Missão no Brasil está ligada a uma página importante das relações entre a Igreja e o Estado e, por isso, não se pode negligenciá-la ${ }^{7}$.

A pesquisa realizada nos rendeu um extenso e minucioso Banco de Dados que necessita ainda ser finalizado para uma posterior publicação on-line na home page do Santuário do Caraça, que é acessada por turistas e pesquisadores, brasileiros ou não. Esta etapa do trabalho vem sendo desenvolvida e atualmente conta mais com a boa vontade dos pesquisadores do que com financiamento, o que vem sendo uma de nossas iniciativas.

O banco de dados, ao lado dos documentos organizados, identificados e higienizados, nos deu as condições para a organização e divulgação dos resultados obtidos para a comunidade em geral. Por comunidade, entendemos aqui não só aquela local e institucional, formadas pelos visitantes do Santuário do Caraça (hóspedes, pesquisadores e principalmente estudantes do ensino fundamental, médio e superior) e acadêmica (docentes, discentes e funcionários da Universidade Federal de Viçosa), mas também por todos os que se interessam pela História das Minas Gerais, agentes multiplicadores de nossa cultura.

Pensando nessa questão, organizamos duas atividades em um evento tradicional no Caraça nos meses de outubro de todo ano. Estamos nos referindo à Semana do Livro, da Biblioteca e da Criança, realizada anualmente no Caraça. Em 2011, houve palestras, exposições fotográficas e bate-papo com todos os visitantes, na maioria alunos e professores da região de Catas Altas. Além de uma visita histórica e ambiental, os alunos participaram de oficinas temáticas, como a de teatro e música, e de rodas de leitura. No final de todos os dias, foram sorteados livros infanto-juvenis para os alunos participantes.

A palestra sobre o tema "Religião e Religiosidade na História e perspectivas de pesquisa” proferida pela Coordenadora, acompanhada dos seguintes pesquisadores: Flávio Teixeira, bolsista do projeto, Ítalo Domingos Santirocchi, Doutor em História pela Pontifícia Universidade Gregoriana de Roma e Gustavo de Souza Oliveira, Doutorando em História Cultural pela UNICAMP, discutiu o percurso da produção historiográfica acadêmica no que se refere à História das Religiões e Religiosidades, focando na vida de personalidades do meio religioso que tiveram inserção na vida social dos habitantes das Minas Gerais, tal como D. Viçoso. 
Além do evento acima, organizamos uma exposição temática intitulada "D. Viçoso, o devoto", cujo objetivo era explorar um lado da personalidade desse Bispo ainda pouco mostrada pela historiografia e fazer os visitantes do Caraça, na maior parte alunos de escolas públicas, entrarem em contato com a História dos Padres da Congregação da Missão e seu trabalho na região de Catas Altas. A mostra contou com objetos e outros documentos sob a guarda do Santuário.

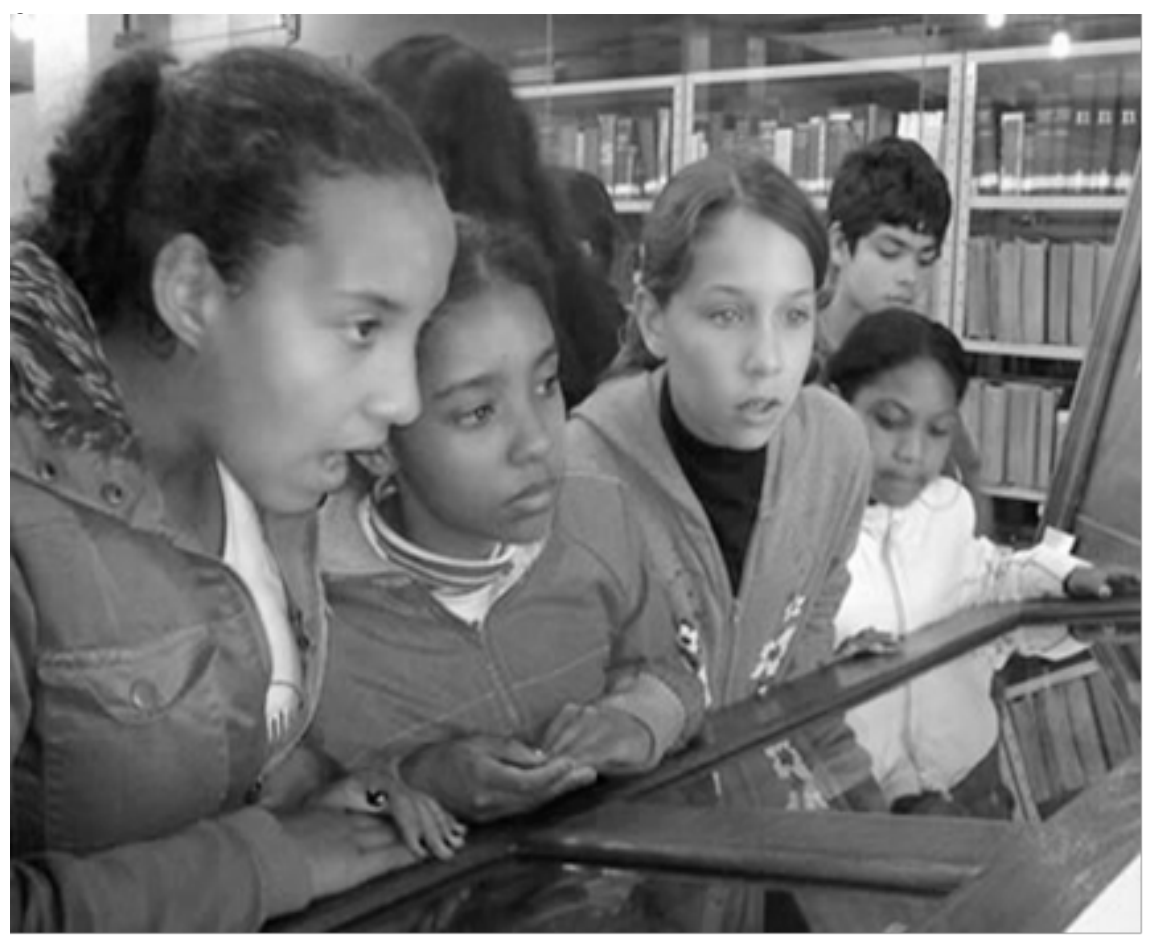

Figura I - Estudantes visitam a exposição temática D. Viçoso, o devoto.

Fonte: Disponível em: http://www.santuariodocaraca.com.br/visitantes/2011/ XI_semana_do_livro_da_biblioteca_e_da_crianca_no_caraca.php $>$. Acesso em 04 de setembro de 2012.

Utilizamos também fotografias do próprio acervo que mostraram a relação entre os objetos e as imagens do prelado. Por exemplo, há nas imagens D. Viçoso segurando um livro e entre seu acervo há menção do livro de S. Ligório. Essa relação só é possível se estivermos atentos aos sinais na documentação tanto material quanto imaterial. A bibliografia disponível sobre o prelado toca, vez ou outra, no perfil devocional que humaniza e diviniza D. Viçoso simultaneamente. O principal objetivo desta exposição era demonstrar à comunidade uma "outra face" de D. Viçoso, tido sempre como figura austera e pronta para a "inquisição" dos habitantes "imorais". 
Folders (financiados pela Fundação Arthur Bernardes - FUNAR$\mathrm{BE}$ ) e Banners informativos foram compostos para a distribuição e exposição aos visitantes nas dependências do Museu do Caraça durante o evento. Além disso, eventos, como a Semana de Integração Acadêmica, organizada pela UFV, foram espaços importantes à divulgação dos trabalhos, permitindo a troca de experiências.

No que se refere às dificuldades encontradas para a execução deste projeto, talvez a maior tenha sido a falta de material adequado para a digitalização das fontes estudadas, que poderia ser otimizada com equipamentos eletrônicos como scanner planetário e câmera fotográfica de alta resolução. Todavia, os materiais oferecidos pelo Departamento de História da UFV e pelo próprio Santuário do Caraça ajudaram na execução das atividades que se faziam necessárias àquele momento.

\section{CONSIDERAÇÕES FINAIS}

De acordo com o parecer feito pela administração do Santuário do Caraça, bem como pela comunidade envolvida no projeto, os resultados foram satisfatórios no que concerne ao planejamento, organização e execução. Os objetos pessoais de um importante prelado de Mariana e de Minas Gerais, D. Viçoso, muitas vezes desconhecido pelos próprios mineiros, estavam em condições lamentáveis e sem o menor trato. Lembremos que a intenção é ampliar o projeto com o tratamento adequado dos outros objetos, contando com o apoio de especialistas em restauração. Com o projeto, foi possível não só identificar as peças, bem como organizá-las para um posterior processo de arquivamento. Esse acervo permanece no Santuário do Caraça e ainda precisa ser adequado a uma estrutura maior, como um museu e uma sala de pesquisa digital. Isto será se possível, um próximo passo a ser dado em outros projetos que possibilitem a aquisição e o custeio de tais ações. Concomitantemente, há também a ideia de publicação de paradidáticos, que poderão ser utilizados por escolas da região, e textos acadêmicos que tratem não só a importância daquele patrimônio, bem como da sua história.

Acreditamos que esse é um bom exemplo da relação entre pesquisa, ensino e extensão tão escassa em muitos projetos, cujo foco ainda é, em grande parte, uma pesquisa voltada para um público muito restrito de pessoas. 


\section{REFERÊNCIAS BIBLIOGRÁFICAS}

ANDRADE, M.G. A Educação Exilada - Colégio do Caraça. Belo Horizonte: Autêntica, 2000.

LEITE, A.C.; LEITE, M.J. Saudades e Lembranças. 1946. In: ANDRADE, M.G. A Educação Exilada - Colégio do Caraça. Belo Horizonte: Autêntica, 2000.

SOUTO, L.V. Dispersos: vida e obra de um escritor esquecido. 1936. In: ANDRADE, M.G. A Educação Exilada - Colégio do Caraça. Belo Horizonte: Autêntica, 2000. 


\section{NOTAS:}

1 Segundo Pe. José Tobias Zico, embora seja controversa a origem de Irmão Lourenço, sabe-se por meio de raras descrições, que teria fugido de Portugal por crime de traição, sendo condenado à morte junto com sua família. A vida desse eremita é desconhecida e poucos indícios nos permitem a investigação mais meticulosa. Se foi condenado ou não por traição não há certeza, mas veio para o Brasil e instalou na Serra do Espinhaço o Hospício Nossa Senhora Mãe dos Homens, onde hoje é o Caraça. Cf: ZICO, Pe. José Tobias, C. M. Caraça, Peregrinação, Cultura e Turismo. Minas Gerais: Editora Littera Maciel, 1988. p. 16.

${ }^{2}$ A Congregação da Missão foi fundada na França, em 1625 por São Vicente de Paulo. Os congregados recebem comumente o nome de Lazaristas por terem, na França, habitado a casa que pertenceu ao Priorado de São Lázaro. São também conhecidos por Padres Vicentinos ou Missionários.

3 Dos estudos que abordam a história do Colégio do Caraça, podemos destacar a pesquisa de Mariza Guerra de Andrade, A Educação Exilada - Colégio do Caraça. No que se refere à atuação evangelizadora realizada pelos lazaristas portugueses no Caraça, destaca-se a dissertação defendida em 1970 por José Ferreira Carrato na USP, intitulada O Caraça Português (ainda não publicada, cópia mimeografada na Biblioteca do Caraça) e de José Maurílio Camello, Caraça - Centro Mineiro de Educação e Missão (1820 - 1830). Belo Horizonte, Imprensa Oficial, 1973; ambos ex-alunos do extinto Colégio.

4 O modelo de ensino do Caraça, segundo Mariza Guerra de Andrade (2000), assemelhava-se ao estilo francês com a introdução de reclusão e disciplina. Na verdade, esse é um estilo de Seminários beneditinos medievais que os franceses retomaram no período moderno. O estudo dos mosteiros de Cluny e Cister pode ajudar a entender isso. Ver: A Espiritualidade na Idade Média Ocidental. Séculos VIII a XIII. Tradução Lucy Magalhães. Rio de Janeiro: Jorge Zahar, 1995.

5 A equipe formada para o desenvolvimento das atividades contava com a participação, além da comunidade acadêmica da UFV, do Diretor da RPPN - Santuário do Caraça, Pe. Wilson Belloni e da Bibliotecária Vera Lúcia Garcia. Auxiliaram também para a pesquisa bibliográfica e correção de termos eclesiásticos o Pe. Lauro Palú; Diretor do Colégio São Vicente de Paulo localizado no Rio de Janeiro. Contava ainda com a participação voluntária de Pe. Marcus Alexandre, na época em Missões no Vale Jequitinhonha; Gustavo de Souza Oliveira, doutorando pela UNICAMP e Marcella de Sá Brandão, tutora do curso à distância da UFV e pesquisadora de História da Igreja Católica.

6 Vale ressaltar que desde 1916, no Arcebispado de D. Silvério Gomes Pimenta, há um processo de beatificação do Bispo em fase de tramitação no Vaticano.

${ }^{7}$ Vários estudos têm-se preocupado detidamente com a ação episcopal nas esferas religiosa (clerical) e laica. Podemos citar o trabalho de Maurílio Camello, D. Antonio Ferreira Viçoso e a reforma do clero em Minas Gerais no século XIX (1986), cujo objetivo é pensar o papel do Bispo de Mariana na constituição da educação mineira e sua inserção no cenário social. Seguindo a tendência de outras instituições de ensino, o Grupo de Pesquisa Igreja e Cultura Religiosa, do Departamento de História da UFV, organizou um dossiê intitulado Cultura religiosa em Minas Gerais para a Revista de Ciências Humanas daquela instituição, onde se podem ler alguns dos trabalhos de pesquisa desenvolvidos pelo Grupo. Para tanto ver: MARTINS K. \& OLIVEIRA, Gustavo. (org.). Dossiê: Cultura Religiosa em Minas Gerais. Revista de Ciências Humanas/ Universidade Federal de Viçosa, Centro de Ciências Humanas, Letras e Artes. - Vol. 11, nº 2, 2011. 